\title{
Analysis of red pepper marketing: evidence from northwest Ethiopia
}

\author{
Abebe Birara Dessie ${ }^{1 *}$, Tigabu Dagnew Koye ${ }^{1}$, Abebe Dagnew Koye ${ }^{1}$ and Asmamaw Alemu Abitew ${ }^{2}$
}

\author{
*Correspondence: \\ a.birara@yahoo.com \\ ${ }^{1}$ Department \\ of Agricultural Economics, \\ College of Agriculture \\ and Environmental Science, \\ University of Gondar, P.O. BOX \\ 196, Gondar, Ethiopia \\ Full list of author information \\ is available at the end of the \\ article
}

\begin{abstract}
Red pepper is the world's second important vegetable ranking after tomatoes. It is the most common spice type which is produced for both commercial and consumption purposes due to its great role in flavoring, food coloring and source of vitamins and minerals. It is also an important cash crop for households and 68\% production is for commercial purpose in Amhara region of Ethiopia. However, empirical evidence is lacking on market chain of red pepper in northwest Ethiopia. Therefore, this research was attempted to analyze the market chain of red pepper and the factors that determine the supply of red pepper to the market. Primary data were collected through a semi-structured interview's schedule administered on 385 red pepper producers and 47 traders selected using simple random sampling technique. Moreover, the survey was supplemented by using secondary data, focus group discussions and key informant interviews. Furthermore, combinations of data analysis methods such as the descriptive and econometrics model were used for data analysis. The producers' survey result revealed that $92.47 \%$ of red pepper output was supplied to the market. Moreover, the main receivers of red pepper output were district wholesalers, district retailers and district assemblers (collectors) who possess 60.2\%, 13.25\% and 10.25\%, respectively. This implies that district wholesalers took the lion share across the red pepper market channels. The remaining amount were traded by rural retailer and district urban wholesalers (about 12.12\%). Furthermore, the multiple linear regression model result revealed that various policy-relevant variables such as access to extension $(p<0.1)$, yield $(p<0.01)$, experience $(p<0.1)$, off-farm income $(p<0.05)$ and market price $(p<0.01)$ influenced the marketable supply of red pepper significantly. Generally, red pepper is one of the most important spice which is mainly produced for commercial purpose yet various production and marketing constraints negatively influenced. Therefore, spice producers, development agents, agricultural experts, research institutions, the Ethiopian government and partner organizations should give special attention for extension service, introducing productive and disease-resistant pepper varieties and infrastructure development to enhance the production and commercial value of red pepper at national and international levels.
\end{abstract}

Keywords: Red pepper, Market chain, Supply, Trader, Multiple linear regression, Ethiopia 


\section{Background}

Ethiopia is a country with different agroecological zones that are favorable for horticultural crop production for both consumption and commercial purposes at local, national and international levels. In the country, more than 14 types of spices are grown, namely pepper, paprika, turmeric, fenugreek, garlic, korarima, coriander, capsicum, ginger, cardamom, black cumin, white cumin and basil (Etissa 1998). Even though Ethiopian smallholder farmers produce vegetables for different purposes, the areas of production and its contribution to the country's total GDP are very low. Similarly, the vegetable production and its coverage constitute about $2.95 \%$ and $1.43 \%$ from the total crop production at national level (CSA 2013).

Vegetable production and marketing is becoming the most common activity in the agricultural sector of the country following high emphases given for the development of irrigation system by the Ethiopian government to small-scale commercial farmers. According to Haji (2008), the major share (1.4 million tons) of vegetable and fruits is consumed locally and only $4.5 \%$ of the total production is exported to international market. Similarly, Ethiopian vegetable and fruit products are mainly traded to the regional markets, but $90 \%$ of exported output was exported to neighboring countries like Djibouti and Somalia (EHDA 2012). Moreover, export earnings (value) of vegetable and fruit has increased from 31.7 million dollars (base year of GTP) to 45.7 million dollars in the year 2013/2014 (MoA 2014).

Vegetable production has a significant role in reducing poverty through generating income, improving the nutrition status of the people and employment generation. According to Lumpkin et al. (2005), vegetable production is a labor-intensive task and generates high employment opportunities for different classes of households. However, in most of the developing countries including Ethiopia, production of horticultural product is seasonal in nature and price is inversely related to the amount of supply. This implies that during the peak season, prices decline and vice versa. The situation is worsened by the perishability of the products and poor storage facilities. Thus, $25 \%$ of the product is damaged along the marketing channel before reaching the final consumers (Emana and Gebremedhin 2007).

Pepper is an important vegetable and spice crop which was originated in Mexico and Central America regions and subsequently spread into Africa and Asia. It is the world's most important type of spice which provides nutritional value to consumers, particularly vitamin A and E, flavoring and coloring food (Boseland and Votava 2000). In Ethiopia, red pepper is an important spice and vegetable crop which is mainly produced by smallholder farmers in Amhara, SNNPRS and Oromia regions (EEPA 2008). Similarly, the share of Amhara region in the total production of red pepper in the country constitutes 25\%, next to Southern Nations, Nationalities, and Peoples' Region (SNNPRS), which produces about $64 \%$ of the total production in the country. Moreover, on average $68 \%$ of pepper production is for commercial purpose in the region (CSA 2008). Furthermore, the main processed product of red pepper, oleoresin, is exported to different countries and the spiced ground is supplied to Ethiopian local markets. Oleoresin that is used for food coloring is extracted from red pepper for export purpose. The deep red-colored cultivars have a very high processing demand in Ethiopian local market (EEPA 2008). Pepper is also the most common food which 
is added in most Ethiopian traditional meals (Roukens and Tamrat 2005). Therefore, agricultural market plays a significant role to deliver such products to consumers at right time with right price.

Agricultural marketing is the main driving force for economic development and has a guiding and stimulating impact on production and distribution of agricultural produce. However, the Ethiopian agricultural output markets are characterized by poor infrastructure, small numbers of trader, lack of credit access, high handling and marketing costs, imperfect market information between buyers and sellers and weak bargaining power of farmers (Haji 2008). Similarly, in the absence of advanced marketing system, smallholder farmers are forced to sell and supply a large volume of agricultural product to the market at low prices (Thakur et al. 1997). Therefore, the poor agricultural marketing system, disease and unstable price of pepper discourage farmers to produce more agricultural products including red pepper.

Similarly, the major factors that affect marketable supply of red pepper were market distance, quantity of pepper produced, frequency of contacts with extension agents and access to market information (Mussema 2006). Despite the significance of pepper in Ethiopian economy and the current income-generating capacity of pepper for the smallholder producers as compared to its magnificent potential in the country, it has not been given due attention. Moreover, red pepper in Amhara region is produced for consumption and marketing purposes. In rural areas, red pepper is highly consumed not only in regular dishes but in other ceremonial events. In Amhara region, there is a high potential of red pepper production but the storage facilities, transportation, linkages with traders, quality controlling mechanisms, market information and price settings are weak and need to be further investigated (BoA 2017).

Though there is a high potential of production of red pepper in North Gondar Zone of Amhara region, not much research has been done so far on marketing chain of red pepper. Therefore, this study was intiated to empirically answer the following four key research questions: (1) What are the major actors involved in red pepper market in the study area? (2) What looks like the marketing channels of red pepper? (3) Which factor affects market supply of red pepper in the study area? And (3) what are the major production and marketing constraints? Therefore, this study can reduce the information gap on the subject and contributing to work better on improved strategies for reorienting marketing system for the benefit of producers, traders and consumers.

\section{Research methodology}

\subsection{Description of the study area}

The study was conducted in North Gondar Zone, Ethiopia. The zone is located in the northwestern part of the country between 11 and 13 north latitude and 35 and 35 east longitudes $738 \mathrm{~km}$ far from Addis Ababa. The zonal capital is Gondar city, and geographically, the city is located at $12^{\circ} 35^{\prime} 60.00^{\prime \prime} \mathrm{N}$ latitude and $37^{\circ} 28^{\prime} 0.01^{\prime \prime} \mathrm{E}$ longitudes with an average elevation of 2133 meters above sea level. The total area of the Administrative Zone is 50,970 square $\mathrm{km}$. The low lands contain some of the largest tracts of semiarid natural forest remaining in northern Ethiopia. The zone also has a total population of $2,921,470$ (84.12\% rural and $15.88 \%$ urban) of which $51 \%$ are men (Abate et al. 2019; CSA 2007). According to zone agriculture department, farmers used irrigation 
mainly for the production of vegetables such as onion, tomato, cabbage, pepper, potato and very often cereals such as maize and others. They also used mixed farming systems (i.e., livestock rearing and crop productions). The study was conducted in two main red pepper producer potential districts, namely Takusa and Dembia (Fig. 1).

\subsection{Data types, sources and methods of data collection}

A combination of quantitative and qualitative data was collected from primary and secondary sources. The research adopted a cross-sectional survey rather than longitudinal survey to collect such data, since the latter requires taking a repeated measurement on continuous bases that have cost and time implications. However, cross-sectional survey requires one-time data collection and analysis which in turn is time-saving and cost-effective (Kothari 2004). Therefore, this study was designed to undertake a crosssectional survey to collect the primary data. The primary data were collected using semi-structured questionnaire. Moreover, secondary data were sourced from different published and unpublished sources to enrich the investigation. Furthermore, the survey was supplemented by using focus group discussions and key informant interviews.

\subsection{Sample size and sampling techniques}

A multistage sampling technique was used to select sample producers. In the first stage, Takusa and Dembia districts were selected purposively due to high potentials of red pepper production. In the second stage, eight largest red pepper-producing kebeles/ villages, namely Mekonta, Chemera, Banbaro, Deber-zuria, Guramba Michael, Arebia, Achera and Gebaba-salge, were purposively selected in consultation with district agriculture office experts due to the high potentials of production and best smallholder farming experience in red pepper production and marketing. In the third stage, 385 red pepper producers were selected using systematic random sampling technique. However, in calculating the sample size, the following assumption is used regarding the value of $p$.

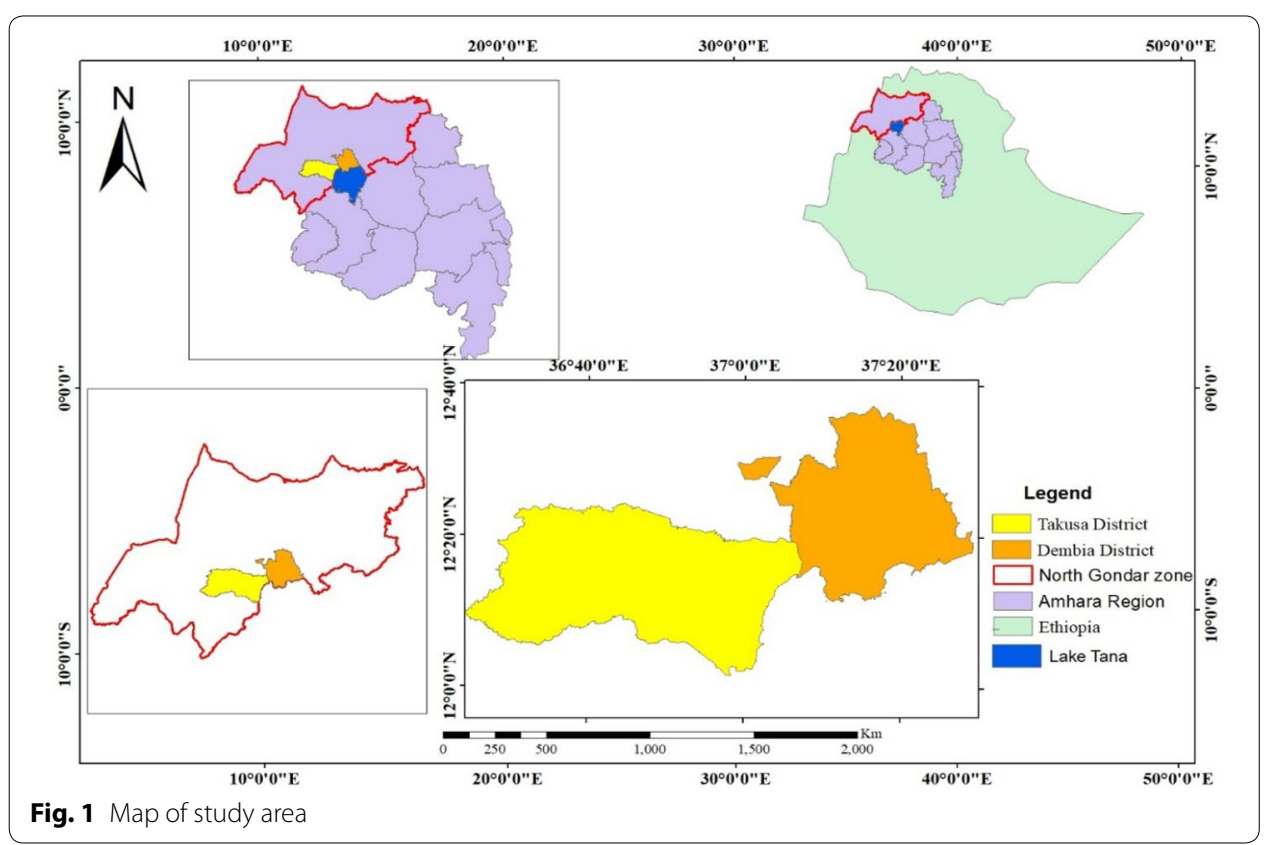


When calculating the sample size for proportion, there are two situations to consider. First, if some approximation of $\mathrm{P}$ is known (example, from a previous study), that value can be used in the formula. Second, if no approximation of $\mathrm{P}$ is known, one should use $p=0.5$. This value will give a sample size sufficiently large to guarantee an accurate prediction (Ott and Longnecker 2010). Hence, the required sample size is determined by (Cochran 1977).

$$
n=\frac{Z^{2} p q}{e^{2}}
$$

where $n=$ sample size; $Z=$ confidence level $(\alpha=0.05) ; p=0.5 ; q=1-p$; and $e=0.05$ (allowable error). $Z=1.96$; hence, $n=\frac{1.96^{2}(0.5 * 0.5)}{0.05^{2}}=385$.

Moreover, the sample traders were selected randomly based on the number of wholesalers' assemblers and retailers participating in red pepper marketing. However, to select sample traders, first the sites for red pepper market were identified; then, out of the total traders identified, 47 sample traders were selected randomly based on proportion to the number of wholesalers, retailers and assemblers in the identified market.

\subsection{Data analysis and model specification}

To effectively handle and analyze the diverse data collected from the field, traders and household heads, a combination of descriptive analysis methods (frequencies, percentages, and means) and econometrics model i.e. multiple linear regression model was used. Multiple linear regression model was used to analyze factors affecting red pepper market supply in northwest Ethiopia. Multiple linear regression analysis is important for testing both economic theories and evaluating policy effects for non-experimental data because it can accommodate many explanatory variables that may be correlated (Maddala and Lahiri 1992). Unlike simple regression analysis, multiple linear regression analysis is more amenable to ceteris paribus analysis because it allows us to explicitly control many other factors which simultaneously affect the dependent variable. Greene (2003) also stated that multiple linear regression model is selected for its simplicity and practical applicability. To find out the impact of factors on market supply of red pepper, the functional relationship is specified in Eq. 2.

$$
y=f\left(X_{1}, X_{2}, X_{3}, X_{4}, X_{5}, X_{6}, \ldots, X_{n}, \varepsilon_{k}\right)
$$

where $y=$ market supply of red pepper (measured in quintals), $x_{n}=$ explanatory variables and $\varepsilon_{k}=$ stochastic error term.

The general form of the multiple linear regression models for this study is expressed in Eqs. 3 and 4:

$$
y=\beta_{0}+\beta_{1} X_{1}+\beta_{2} X_{2}+\beta_{3} X_{3}+\beta_{4} X_{4}+\beta_{5} X_{5}+\beta_{6} X_{6},+\cdots+\beta_{k} X_{n}+\varepsilon_{k}
$$

where $y=$ dependent variable explained by different explanatory variables, $X_{n}=$ independent variable used to explain dependent variable, $\beta_{0}=$ intercept of regression model, $\beta_{k}=$ parameters associated with explanatory variable and $\varepsilon_{k}=$ stochastic error term.

This can be written as matrix notation:

$$
y=x \beta+\varepsilon, \quad y=\left[\begin{array}{c}
y_{1} \\
y_{2} \\
\vdots \\
y_{n}
\end{array}\right], \quad x=\left[\begin{array}{cccc}
x_{11} & x_{12} & \cdots & x_{1 k} \\
x_{21} & x_{22} & \cdots & x_{2 k} \\
\vdots & \vdots & \vdots & \vdots \\
x_{n 1} & x_{n 2} & \cdots & x_{n k}
\end{array}\right], \quad \beta=\left[\begin{array}{c}
\beta_{0} \\
\beta_{1} \\
\vdots \\
\beta_{k}
\end{array}\right] \text { and } \varepsilon=\left[\begin{array}{c}
\varepsilon_{1} \\
\varepsilon_{2} \\
\vdots \\
\varepsilon_{n}
\end{array}\right] \text {, }
$$


Prior to the regression analysis, multicollinearity test, heteroscedasticity diagnosis, linearity test, omitted variable and normality test were undertaken to filter the variables that are highly dependent. According to Gujarati (2004), variance inflation factor (VIF) is used to check multicollinearity among continuous variables. Before fitting important variables in the model, it is necessary to test multicollinearity problem among continuous variables and check associations among discrete variables, because it highly affects the parameter estimates. As a rule of thumb, if the value of VIF is greater than 10, the variables are said to be highly collinear. Mathematically, it can be expressed in Eq. 5:

$$
\mathrm{VIF}=\frac{1}{1-R_{j}^{2}}
$$

where $R_{j}^{2}$ is the multiple correlation coefficients between explanatory variables, the larger the value of $R_{j}^{2}$, the higher the value of VIF $\left(X_{j}\right)$ causing collinearity in the variable $\left(X_{j}\right)$. Likewise, the multicollinearity between discrete variables can be calculated using contingency coefficient. The value ranges between 0 and 1,0 indicating no association between the variables and value close to 1 indicating a high degree of association between variables. As a rule of thumb, if the value of $C C$ is greater than 0.75 , the variables are said to be collinear. Mathematically, it can be expressed in Eq. 6 .

$$
C C=\sqrt{\frac{\chi^{2}}{N+\chi^{2}}}
$$

where CC is the contingency coefficient, $\chi^{2}-$ Chi-square test, and $N-$ total sample size.

\section{Results and discussion}

\subsection{Demographic and socioeconomic characteristics of households}

Out of 385 sample producers, $95.32 \%$ and $4.68 \%$ were male- and female-headed households, respectively. The average age, lag price, distance to development center, family size, output, livestock number, market distance, land size allotted for pepper and farming experience of producer were also 48.31, 41.90, 2.54, 18.87, 6.43, 9.72, 8.87, 5.17 and 0.34 , respectively (Table 1$)$. Likewise, the level of education ( $48.31 \%$ and $51.69 \%)$ of them was illiterate and literate, respectively. Moreover, the majority of producers $(61.30 \%$, 63.64\% and 78.44\%) were got credit service, market information and extension service, respectively. Furthermore, most producers $(95.32 \%)$ were a member of farmers' cooperative (Table 1).

\subsection{Marketing channels of red pepper}

A marketing channel is a business structure of interdependent organizations that deliver products from the point of production to the ultimate consumer (Kotler and Armstrong 2003). Therefore, analysis of marketing channels of agricultural product helps to know the alternative routes of product flow from the point of production to final consumption. In production season of 2017/2018, amount of red pepper supplied to market was 136,645 quintal. This calculation was done by taking sample traders' data from different district markets. The pepper marketing channels indicated in Fig. 2 revealed that red pepper passes from producers to consumers in very long and complicated channels of 
Table 1 Mean and proportion households' characteristics $(N=385)$

\begin{tabular}{llcr}
\hline Continuous variables & Mean & SD \\
\hline Age in years & & 48.31 & 0.54 \\
Family size in number & 6.43 & 0.12 \\
Land size allotted to red pepper in ha & & 0.34 & 0.01 \\
Farming experience in years & 18.87 & 0.59 \\
Output in quintals & 9.72 & 0.42 \\
Lag price in ETB/kg & & 41.90 & 1.58 \\
Distance to development center in km & & 2.54 & 0.14 \\
Distance to the nearest market in km & & 5.17 & 0.25 \\
\hline Dummy variable & Response & Frequency & $\%$ \\
\hline Extension service & Yes & 302 & 78.44 \\
& No & 83 & 21.56 \\
Sex & Male & 367 & 95.32 \\
Education status & Female & 18 & 4.68 \\
& Illiterate & 199 & 51.69 \\
Market information & Literate & 186 & 48.31 \\
Cooperative membership & Yes & 245 & 63.64 \\
Credit access & No & 140 & 36.36 \\
& Yes & 367 & 95.32 \\
& No & 18 & 4.68 \\
& Yes & 236 & 61.30 \\
& No & 149 & 38.70 \\
\hline
\end{tabular}

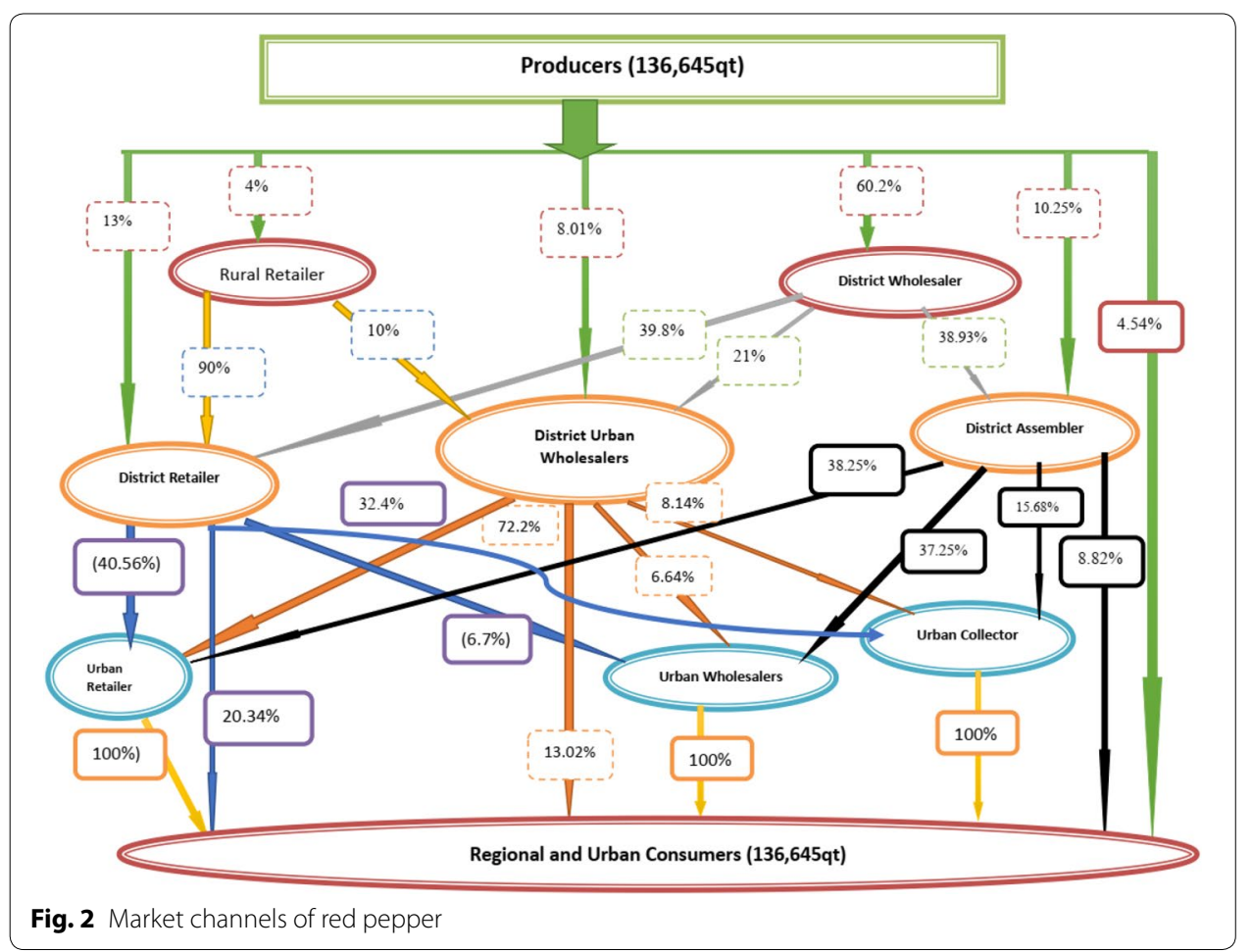


intermediaries such as rural retailer, district retailers and wholesalers, district and urban assemblers, urban wholesalers and collectors. As shown in Fig. 2, district wholesalers, district retailers and district assemblers (collectors) received 60.2\%, 13\% and 10.25\%, respectively. Hence, district wholesalers took the lion share across the red pepper market channels. The remaining amount was traded by rural retailer (4\%) and district urban wholesalers $(8.01 \%)$. Moreover, $4.43 \%$ of red pepper output was handled by producers and directly sold to consumers. Comparatively, producers-district wholesaler-district retailer-urban retailer-consumer channels are the dominant channels as per the volume of pepper flows across the channels followed by producer-district wholesaler-district urban assembler-urban retailer-consumer and producer-district wholesaler-district urban wholesaler-urban retailer-consumer, respectively. The other channels might not be a competition due to limited working capital and lack of experiences. This study is in line with the finding of (Tesfaw and Alemu 2013).

\section{Production and marketing constraints}

\subsection{Production constraints}

Red pepper is the most important vegetable and spice crop which is mostly produced by smallholder farmers in three regions of Ethiopia, particularly in Amhara, Oromia and Southern Nations, Nationalities, and Peoples' regions. However, various institutional, environmental and socioeconomic factors influenced the production of red pepper in Ethiopia. The result presented in Fig. 3 revealed that the main red pepper production constraints were poor access to agricultural inputs (92.99\%), prevalence of red pepper disease (78.44\%), lack of new varieties and poor productivities of local variety $(72.73 \%)$ and shortage of land (65.97\%). Moreover, red pepper production by its nature is labor intensive (57.29\%), particularly in planting, transplanting, hoeing and harvesting.

\subsection{Marketing constraints}

Red pepper is an important cash crop not only marketed in national market but also for international market due to its flavoring, color to food and vitamin and mineral source. However, various factors influenced the commercial value of red pepper output. The result in Fig. 4 revealed that the most common red pepper marketing constraints

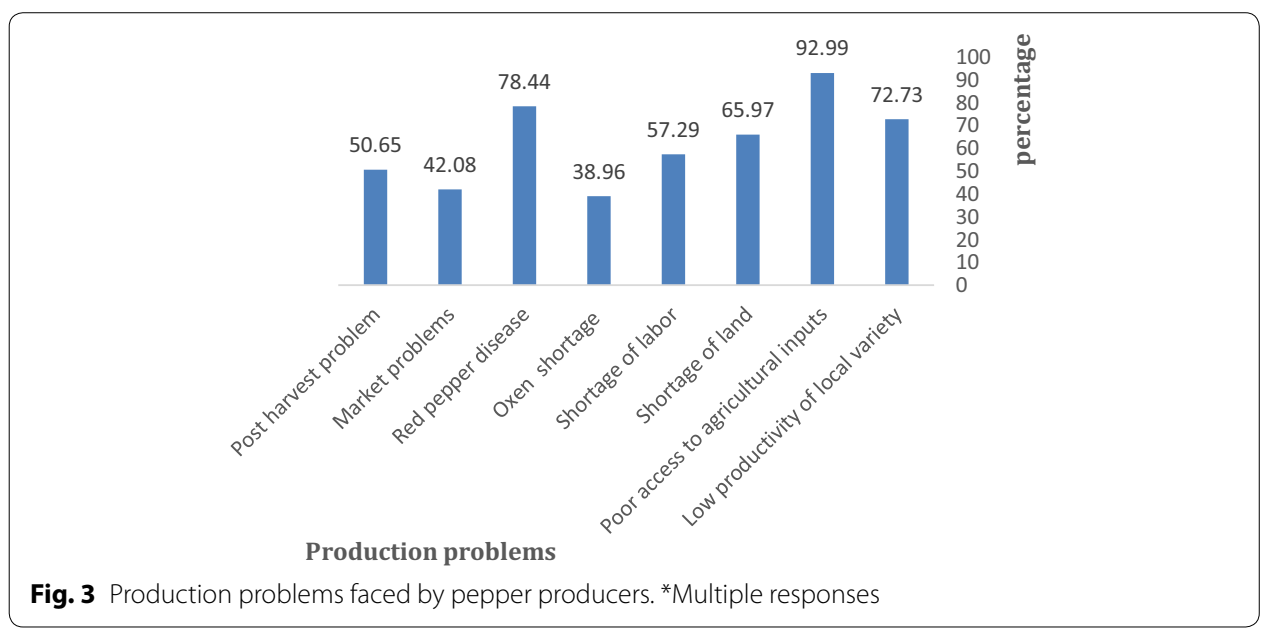




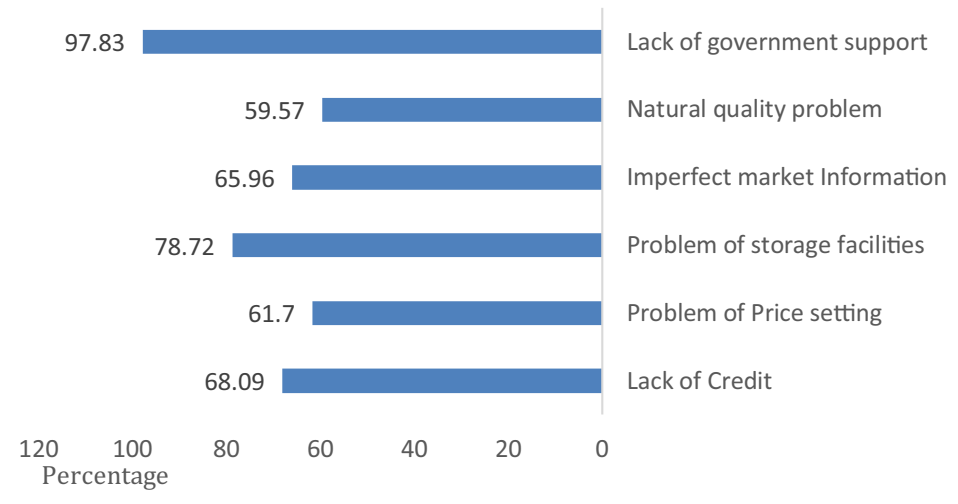

Fig. 4 Marketing problems faced by pepper producers. *Multiple responses

were lack of government support (97.83\%), problem of storage facilities (78.72\%), lack of credit service $(68.09 \%)$, lack of perfect information between buyers and seller about market (65.96\%), problem of price setting (61.7\%) and natural quality problem (59.57\%).

\subsection{Determinants of market supply of red pepper}

To determine factors influencing red pepper market supply, multiple linear regression model was used. The degree of multicollinearity among the explanatory variables has been tested using variance inflation factor (VIF) test for continuous variables and contingency coefficient $(\mathrm{CC})$ test for dummy variables. Hence, the post-estimation model result presented in Table 2 shows that the value of variance inflation factor ranges between 1.02 and 1.81, while the contingency coefficient was 0.165 , implying that the data have no multicollinearity problems because as rule of thumb the value of VIF and CC was below 10 and 0.75 , respectively. Similarly, Ramsey RESET test was used to check whether the model has omitted variable or not, implying that model has not omitted variable. Moreover, White's test was used to detect heteroscedasticity problems provided that the data have no such problems (Table 2).

Similarly, linearity test was conducted using a linear probability plot test. The test implies that one of the assumptions of multiple linear regression model was satisfied (Fig. 5). Moreover, normality test was conducted using a kernel density estimate. The result presented in Fig. 6 indicated that one of the main assumptions (normality) of multiple linear regression model was satisfied.

Furthermore, the overall significance and fitness of the model were checked with $\mathrm{F}$ value; accordingly, Prob $>F=0.0000$ indicated that the independent variables reliably predicted the dependent variable. Thus, the regression model was adequate since in determining model adequacy features such as the $R^{2}$ and the $F$ value are observed (Gujarati 2007). The result of the econometric analysis indicates that among the ten hypothesized variables included in the model only five variables such as experience $(p<0.1)$, market price $(p<0.01)$, yield $(p<0.01)$, off-farm $(p<0.05)$ and extension service $(p<0.1)$ significantly affect the household marketable supply of red pepper (Table 3 ).

Farmers experience in pepper production positively and significantly affected the volume of red pepper supplied to the market at $10 \%$ levels of significance. The result 
Table 2 Post-estimation tests of multiple linear regression model

\begin{tabular}{|c|c|c|c|c|}
\hline Problems & Types of test used to detect the & roblem & & Status \\
\hline Heteroscedasticity & $\begin{array}{l}\text { White's test } \\
\text { Ho: homoscedasticity against } \\
\text { Ha: heteroscedasticity } \\
\text { chi }^{2}(63)=46.50 \\
\text { Prob }>\text { chi }^{2}=0.9408\end{array}$ & & & $\begin{array}{l}\text { Accept null hypothesis and no } \\
\text { heteroscedasticity }\end{array}$ \\
\hline Omitted variables & $\begin{array}{l}\text { Ramsey RESET test } \\
\text { Ho: model has no omitted variables } \\
F(3,371)=1.44 \\
\text { Prob }>F=0.2319\end{array}$ & & & $\begin{array}{l}\text { Accept null hypothesis }(\mathrm{Ho}) \text { and } \\
\text { model has no omitted variables }\end{array}$ \\
\hline Multicollinearity & $\begin{array}{l}\text { Variance inflation factor test } \\
\text { Variables } \\
\text { Land size } \\
\text { Output } \\
\text { Experience } \\
\text { Age } \\
\text { Market distance } \\
\text { Development distance } \\
\text { Log of farm income } \\
\text { Log selling price } \\
\text { Contingency Coefficient test } \\
\text { Variables } \\
\text { Credit } \\
\text { Extension }\end{array}$ & $\begin{array}{l}\text { VIF } \\
1.81 \\
1.68 \\
1.58 \\
1.49 \\
1.10 \\
1.07 \\
1.07 \\
1.02\end{array}$ & $\begin{array}{l}\text { Tolerance } \\
0.5511 \\
0.5944 \\
0.6333 \\
0.6730 \\
0.9082 \\
0.9341 \\
0.9350 \\
0.9792 \\
\\
\text { Extension } \\
0.165 \\
1\end{array}$ & $\begin{array}{l}\text { The value of VIF and CC was below } \\
10 \text { and } 0.75 \text {. Therefore, there are } \\
\text { no multicollinearity problems } \\
\text { among explanatory variables } \\
\text { used in multiple linear regression } \\
\text { model }\end{array}$ \\
\hline
\end{tabular}

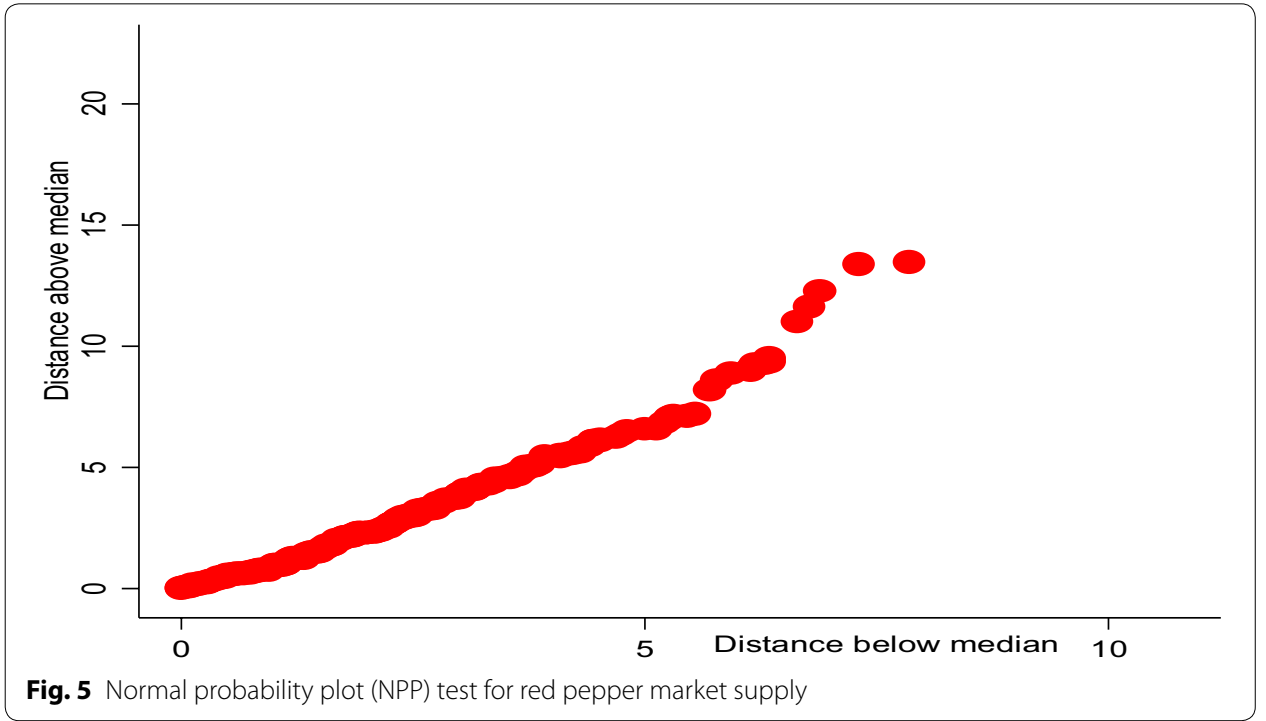

indicates that as the experiences of producers in red pepper production increased by a year, the volume of red pepper supplied to the market also increased by 0.071 quintals. This implies that experienced farmers can produce more as the amount of red 


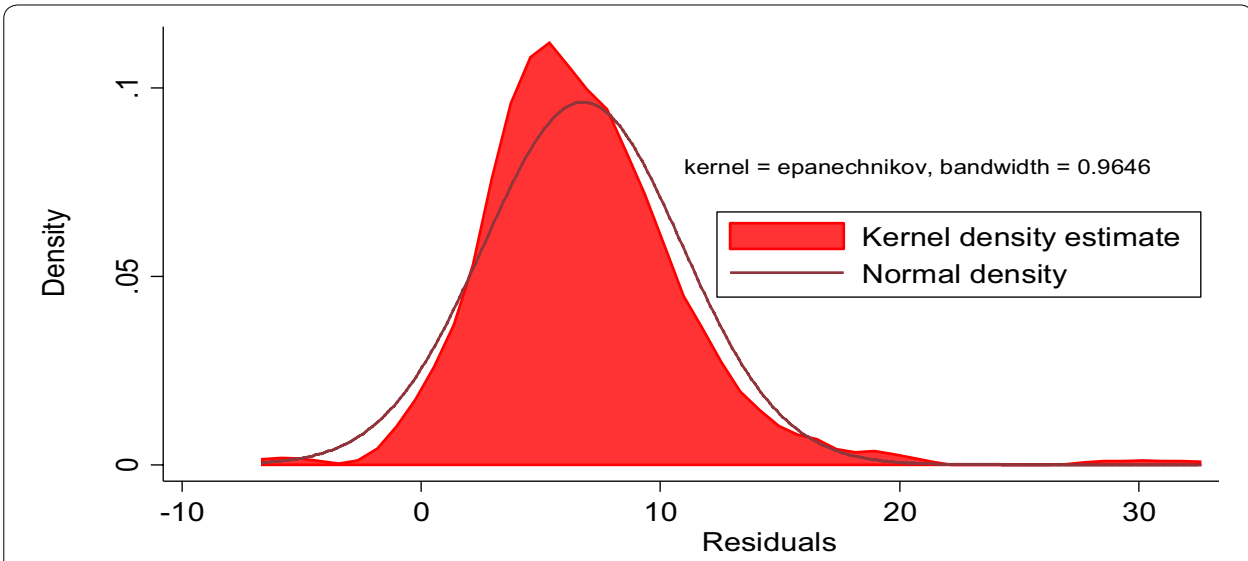

Fig. 6 Kernel density estimate of residuals in multiple linear regression analysis

Table 3 Determinants of red pepper market surplus (OLS result)

\begin{tabular}{llll}
\hline Variables & Coefficients & SE & t ratio \\
\hline Age of households (in years) & 0.035 & 0.046 & 0.76 \\
Experience in red pepper production (in years) & 0.071 & 0.043 & $1.65^{*}$ \\
Size of land for red pepper production (in ha) & 3.760 & 2.465 & 1.53 \\
Amount of red pepper output (in Qt) & 0.347 & 0.064 & $5.44^{* * *}$ \\
Distance to development center (in km) & 0.191 & 0.148 & 1.29 \\
Extension service (1=accessed, 0=otherwise) & 2.021 & 1.117 & $1.81^{*}$ \\
Credit service (1=yes, 0=otherwise) & 0.672 & 0.880 & 0.76 \\
Distance to market (in km) & 0.110 & 0.088 & 1.25 \\
Log off-farm income (in ETB) & -0.565 & 0.224 & $-2.52^{* *}$ \\
Log market price of red pepper (in ETB/Qt) & 2.043 & 0.696 & $2.93^{* * *}$ \\
Constant term & -10.096 & 3.139 & $-3.22^{* * *}$ \\
& Number of obs. $=385$ & & \\
& F (10,374)=10.91 & & \\
\hline
\end{tabular}

Dependent variable is volume of red pepper supplied to market measured in quintals

***, ** and ${ }^{*}$ represent the value statistically significant at 1,5 and $10 \%$ levels, respectively

pepper supplied to market also increases. This study is in line with the finding of Abay (2010), who confirmed that the volume of red pepper supplied to market increases as farmer's experience in red pepper production increases.

Access to extension service positively and significantly influenced the volume of red pepper supplied to the market at $10 \%$ levels of significance. If the pepper producers access extension service, the amount of red pepper supplied to the market also increases by 2.021 quintals. This signifies that access to extension service avails information regarding technology which improves production and affects the marketable surplus postively. The result of this study is in line with the findings of Siziba et al. (2011), Urgessa (2011) and Mussema (2006); they found that access to extension 
service significantly and positively influenced the volume of cereal supplied to the market. Similarly, Rehima and Dawit (2012) revealed that the market supply of red pepper was positively and significantly influenced by extension contact.

Total red pepper production was influenced the amount of red pepper supplied to the market significantly and positively at $1 \%$ levels of significance. The positive coefficient indicates that a one quintal increase in quantity of red pepper production causes to increase the market supply of red pepper by 0.34 quintal, implying that farmers who produce more output also supply more to market. This study is in line with the finding of Abay (2010) who revealed that the amount of pepper produced significantly and positively affects the marketable supply of pepper. Similarly, Rehima and Dawit (2012) stated that total production of pepper has a significant and positive effect on marketed supply of red pepper. Moreover, these results are consistent with the findings of Alemu (2007), Abebe (2009), Gessesse (2009), Omiti et al. (2009), Takele (2010) and Bosena et al. (2011); they depicted that agricultural productions and volume of sales have a positive relationship.

Off-farm income significantly and negatively affected the marketable supply of red pepper at $5 \%$ levels of significance. The result shows that the market supply of red pepper decreased by 0.565 quintal as a source of off-farm income of producers increased by $1 \%$. This implies that farmers who have better non-farm income will not tend to generate cash by selling red pepper because they have an alternative source of income to cover tax, loan and other social requirements. This study is consistent with the previous studies (Omiti et al. 2009; Komarek 2010; Rehima and Dawit 2012); they confirmed that market supply of maize, banana and red pepper was negatively and significantly influenced by off-farm income.

Market prices of red pepper also affect market supply red pepper significantly and positively at $1 \%$ levels of significance. The result also revealed that as the market price of red pepper increased by $1 \%$, the volume of red pepper supplied to the market also increased by 2.043 quintals. This implies that pepper is an important cash crop and its volume supplied to the market increases as the market price increases. This result is consistent with the finding of Dessie et al. (2017), Abay (2010) and Wolelaw (2005); they revealed that market price had a significant and positive effect on marketable supply of red pepper and rice.

\section{Conclusion and recommendation}

Red pepper is an important vegetable and spice crop which is produced by smallholder farmers for both commercial and consumption purposes at local, national and international markets. Therefore, analysis of market chain on red pepper plays an important role in an ongoing or future red pepper marketing, production and supply development plan. However, the production and marketing of red pepper are constrained by various socioeconomic, institutional, biological factors. The finding also revealed that red pepper production is carried out by different actors via different market channels. However, the majority $(60.2 \%)$ of red pepper transaction was handled by district wholesalers and reached final consumers through different market channels. The result from the econometric analysis also revealed that various socioeconomic, demographic and institutional variables such as experience in red pepper production, access to extension, yield and 
market price of red pepper were found to have a positive and significant effect on the volume of red pepper supplied to the market, while amount of off-farm income negatively and significantly influenced the volume of red pepper marketed. The study also implies that experienced farmers produced more output and supplied more product to the market. Access to extension service avails information regarding technology which improves production and marketable surplus. Farmers who produce more output also supply more to market. Farmers who have better non-farm income would not tend to generate cash by selling red pepper because they have an alternative source of income to cover tax, loan and other social requirements. Given the potential of the study area on red pepper production, marketing and its significant role to improve the livelihood of producers, consumers and traders, the following implication has given for the development of production and marketing of red pepper. The study recommends that for holistic red pepper production and marketing among producers, the agricultural research experts, policy makers and development practitioners should have to strengthen local institutions and service providers to develop knowledge, skill and attitudes of farmers and traders on technology adoption, production and marketing of spice in general and particularly in red pepper.

\begin{abstract}
Abbreviations
CSA: Central Statistical Agency; e: Error; EHDA: Ethiopian Horticulture Development Agency; ETB: Ethiopian Birr; EEPA: Ethiopian Export Promotion Agency; BOA: Bureau of Agriculture; Ho: Null Hypothesis; Ha: Alternative Hypothesis; MoA: Ministry of Agriculture; $n$ : Sample Size; SNNPRS: Southern Nations, Nationalities, and Peoples' Region; Z: Confidence Level; VIF: Variance Inflation Factor; CC: Contingency Coefficient.
\end{abstract}

\title{
Acknowledgements
}

The author would like to thank the University of Gondar since financial support for this research was obtained from this institution. Moreover, we thank the data respondents, enumerators and district experts for their valuable response during data collection process.

Authors' contributions

All authors read and approved the final manuscript.

Funding

The University of Gondar provided financial support to complete this research successfully.

Availability of data and materials

The author wants to declare that they can submit the data at any time based on publisher's request. The datasets used and/or analyzed during the current study will be available from the author on reasonable request.

\section{Ethical approval and consent to participate}

Ethical clearance letters were collected from University of Gondar research and community service directorate and North Gondar Zone administrative office to care for both the study participants and the researchers. During survey, official letters were written for each district and kebele/village, informed verbal consent was obtained from each client, and confidentiality was maintained by giving codes for each respondent rather than recording their name. Study participants were informed that clients have a full right to discontinue or refuse to participate in the study. Hence, all participants throughout the research, including survey households, enumerators, the supervisors and key informants, were fully informed of the objectives of the study. They were approached friendly in free moods until the end of this research.

\section{Consent for publication}

Not applicable.

\section{Competing interests}

The authors declare that they have no competing interests.

\section{Author details}

${ }^{1}$ Department of Agricultural Economics, College of Agriculture and Environmental Science, University of Gondar, P.O. BOX 196, Gondar, Ethiopia. ${ }^{2}$ Department of General Forestry, College of Agriculture and Environmental Science, University of Gondar, Gondar, Ethiopia.

Received: 15 April 2019 Revised: 20 May 2019 Accepted: 22 June 2019

Published online: 30 June 2019 
References

Abay A (2010) Market chain analysis of red pepper: the case of Bure woreda, west Gojjam zone, Amhara National Regional State, Ethiopia. M.Sc. thesis presented to Haramaya University, Ethiopia

Abebe A (2009) Market chain analysis of honey production in Atsbi Wemberta District, eastern zone of Tigray national regional state. M.Sc. thesis presented to Haramaya University, Ethiopia

Alemu D (2007) Determinants of smallholder commercialization of food crops: theory and evidence from Ethiopia, vol 745. International Food Policy Research Institute, Washington DC

Abate TM, Dessie AB, Mekie TM (2019) Technical efficiency of smallholder farmers in red pepper production in North Gondar zone Amhara regional state. Ethiopia. J Econ Struct 8:18

BoA (2017) Amhara National Regional State, 2016/2017. Annual Performance Report, Bahir Dar, Ethiopia Boseland P, Votava E (2000) Pepper: vegetable and spice capsicum. CABI Publishing, New York, pp 1-16

Bosena T, Bekabil F, Gebremedhin B, Hoekstra D (2011) Factors affecting cotton supply at the farm level in Metema District of Ethiopia

Cochran WG (1977) Sampling techniques, 3rd edn. Wiley, New York

CSA (2007) Area and Production of Crops. Country Level, Part II, Addis Ababa., 2007

CSA (2008) Area and Production of crops, Annual Statistical Bulletin, Addis Ababa, Ethiopia

CSA (2013) Area and Production of Major Crops (Private Peasant Holdings, Meher Season), Ethiopia

Dessie M, Woldeamanuel T, Mekonnen G (2017) Value chain analysis of red pepper: the case of Abeshge District, Guragie Zone, South Ethiopia. Int J Environ Sci Nat Resour 2(3):01-08

EEPA (2008) Export performance of Agricultural products, Addis Ababa, Ethiopia

EHDA (2012) Ethiopian Horticulture Industry Bulletin, Addis Abeba, Ethiopia

Emana B and Gebremedhin H (2007) Constraints and opportunities of horticulture production and marketing in eastern Ethiopia. DCG report

Etissa E (1998) Research Achievements and Experiences

Gessesse A (2009) Analysis of fruit and vegetable market chains in Alamata, Southern Zone of Tigray: The case of onion, tomato and papaya, 2009, International Livestock Research Institute

Greene WH (2003) Econometric analysis. Pearson Education India, Delhi

Gujarati D (2004) Basic Econometrics. United States Military Academy, West Point, 2004, Tata McGraw-Hill

Gujarati D (2007) Basic econometrics. Tata McGraw-Hill Edition, Delhi

Haji J (2008) An economic efficiency and marketing performance of vegetables in Eastern and Central parts of Ethiopia. Unpublished Doctorial Thesis

Komarek A (2010) The determinants of banana market commercialisation in Western Uganda. Afr J Agric Res 5(9):775-784

Kothari CR (2004) Research methodology: methods and techniques. New Age International, Delhi

Kotler P, Armstrong G (2003) Fundamentos de marketing. Pearson Educación, London

Lumpkin T, Weinberger K, Moore S (2005) Increasing income through fruit and vegetable production opportunities and challenges

Maddala GS, Lahiri K (1992) Introduction to econometrics, vol 2. Macmillan, New York

MoA (2014) The performance report of GTP of the Agriculture Sector from 010/11 - 2013/14, Planning and Programming Directorate, December, 2014

Mussema R (2006) Analysis of red pepper marketing: the case of Alaba and Siltie in SNNPRS of Ethiopia. Haramaya University, Dire Dawa

Omiti JM, Otieno DJ, Nyanamba TO, McCullough EB (2009) Factors influencing the intensity of market participation by smallholder farmers: a case study of rural and peri-urban areas of Kenya. African Journal of Agricultural and Resource Economics 3(1):57-82

Ott R, Longnecker M (2010) Using surveys and experimental studies to gather data. An Introduction to Statistical Methods and Data Analysis. 5th ed. Belmont, CA: Brook Cole, Cengage Learning: p. 1-26

Rehima M, Dawit A (2012) Red pepper marketing in Siltie and Alaba in SNNPRS of Ethiopia: factors affecting households' marketed pepper. International Research Journal of Agricultural Science and Soil Science 2(6):261-266

Roukens O, W. Tadeleand K. Tamrat (2005) Export potential of Ethiopian oleoresins. Ethiopian Export Promotion Department, pp 7-14

Siziba S, Nyikahadzoi K, Diagne A, Fatunbi AO, Adekunle AA (2011) Determinants of cereal market participation by subSaharan Africa smallholder farmer. Journals of Agriculture \& Environmental Studies; 2(1)

Takele, A (2010) Analysis of rice profitability and marketing chain: The case of Fogera Woreda, South Gondar Zone, Amhara national regional state, Ethiopia. MSC thesis presented to Haramaya University, Ethiopia

Tesfaw A, Alemu D (2013) Marketing channel and margin analysis: A case study of red pepper marketing at Jabitehinan District in Northwestern Ethiopia. LAP LAMBERT Academic Publishing, Riga

Thakur DS, Lal H, Thakur DR, Sharma KD, Saini AS (1997) Market supply response and marketing problems of farmers in the Hills. Indian J Agric Econ 52(1):139

Urgessa, M (2011) Market chain analysis of teff and wheat production in Halaba Special Woreda, southern Ethiopia. Msc thesis resented to Haramaya University, Ethiopia

Wolelaw S (2005) Factors determining supply of rice: A study in Fogera district of Ethiopia. An M.Sc. Thesis Presented to the School of Graduate Studies of Alemaya University, Ethiopia

\section{Publisher's Note}

Springer Nature remains neutral with regard to jurisdictional claims in published maps and institutional affiliations. 